\title{
Validation of a method for the estimation of energy expenditure during physical activity using a mobile device accelerometer
}

\author{
Ivan Miguel Pires ${ }^{\mathrm{a}, \mathrm{b}, \mathrm{c},{ }^{*}, \text { Virginie Felizardo }}{ }^{\mathrm{a}, \mathrm{c}}$, Nuno Pombo ${ }^{\mathrm{a}}$, Mario Drobics ${ }^{\mathrm{d}}$, Nuno M. Garcia ${ }^{\mathrm{a}}$ and \\ Francisco Flórez-Revuelta ${ }^{\mathrm{e}}$ \\ ${ }^{a}$ Instituto de Telecomunicações, University of Beira Interior, Rua Marquês d'Ávila e Bolama, 6201-001 Covilhã, \\ Portugal \\ E-mails: impires@it.ubi.pt,virginie@it.ubi.pt,ngpombo@ubi.pt,ngarcia@di.ubi.pt \\ b Altranportugal, Lisbon, Portugal \\ E-mail: ivan.pires@altran.com \\ ${ }^{\mathrm{c}}$ ALLab - Assisted Living Computing and Telecommunications Laboratory, Computer Science Department, \\ University of Beira Interior, Covilhã, Portugal \\ ${ }^{\mathrm{d}}$ Digital Safety \& Security Department, AIT Austrian Institute of Technology, Vienna, Austria \\ E-mail: mario.drobics@ait.ac.at \\ e Department of Computer Technology, Universidad de Alicante, Spain \\ E-mail: francisco.florez@ua.es
}

\begin{abstract}
The main goal of this paper consists on the adaption and validation of a method for the measurement of the energy expenditure during physical activities. Sensors available in a mobile device, e.g., a smartphone, a smartwatch, or others, allow the capture of several signals, which may be used to the estimation of the energy expenditure. The adaption consists in the comparison between the units of the data acquired by a tri-axial accelerometer and a mobile device accelerometer. The tests were performed by healthy people with ages between 12 and 50 years old that performed several activities, such as standing, gym (walking), climbing stairs, walking, jumping, running, playing tennis, and squatting, with a mobile device on the waist. The validation of the method showed that the energy expenditure is underestimated and super estimated in some cases, but with reliable results. The creation of a validated method for the measurement of energy expenditure during physical activities capable for the implementation in a mobile application is an important issue for increase the acceptance of the mobile applications in the market. As verified the results obtained are around $124.6 \mathrm{kcal} / \mathrm{h}$, for walking activity, and $149.7 \mathrm{kcal} / \mathrm{h}$, for running activity.
\end{abstract}

Keywords: Physical exercise, energy expenditure, algorithm, mobile devices, accelerometer

\section{Introduction}

During the last years, the use of mobile devices, e.g., smartphones, smartwatches, and tablets, is increasing $[23,54]$. Sensors are commonly available on these devices, allowing the capture of several physi-

\footnotetext{
*Corresponding author. Tel.: +351 966379785; E-mail: impires@it.ubi.pt.
}

cal and physiological parameters anywhere and at any time [65]. The sensors available on these devices, e.g., accelerometer, gyroscope, magnetometer, and gravity sensors, Global Positioning System (GPS) receiver, microphone, and camera, offer the opportunity to the creation of new health-related systems, including the measurement of the energy expenditure during physical activity. 
The benefits of a regular physical activity are vast [77]. In children and young people (5-17 years) exercise helps to maintain a normal weight, to develop healthy musculoskeletal and cardiovascular tissues and to improve coordination and movement control [77]. For adults (18-64 years) physical activity helps to lower rate of cardiovascular disease, high blood pressure, diabetes type II and depression; reduce the risk of suffering from hip and vertebral fractures, increase the level of muscular and cardiovascular fitness, and ease the control of the weight and body mass composition [78]. In the elderly ( $>65$ years) in addition to the same benefits given to adults, physical activity reduces the risk of falls and improves cognitive functions [79].

There is a vast number of mobile applications for the estimation of the energy expenditure available in the market, but only a few of them have information about the statistical and scientific validity. Commonly, the scientific validity of mobile applications is not verified by the publisher before the submission to the online application stores, therefore, the user may be led into error by assuming that the application has a scientific background and returns valid results, when in fact, it has not [22].

This paper describes the process of adaptation based on the study $[24,25]$ where the estimation of the energy expenditure was assessed for accelerometers and electromyography signals against a golden standard. This paper also addresses the validation of a method for the estimation of the energy expenditure during physical activity, implementing this new method in a mobile application, using unobtrusive sensing on mobile devices. The implementation of a validated method to estimate the energy expenditure may increase the acceptance of the mobile application among users. This paper also presents a study related to the validity of the mobile applications for the estimation of the energy expenditure available in Google Play [64].

The remaining sections of this paper are organized as follows: this paragraph concludes Section 1 and Section 2 presents a background about the validity of the mobile applications for the measurement of the energy expenditure available on the Google Play Store, and a review of the existing research studies on this subject. Section 3 presents a description of the implemented solution. Section 4 presents the validation of the method. Section 5 presents the results of the described method. Section 6 presents the discussion about the method implemented. Section 7 presents the conclusions of this study. At the end, the literature references are presented.

\section{Background}

\subsection{Mobile applications review}

Several mobile applications for the measurement of the energy expenditure during physical activities are available in the online application stores, e.g., Google Play Store [64], and iTunes Store [7]. As these mobile applications should be backed by a research that assures the scientific validity of the mobile applications, the question of the present study consists on the research about the scientific validity of the mobile applications available on the Google Play Store for this purpose.

The mobile applications were included in this review if they met the following criteria: (1) measure the energy expenditure, (2) use sensors, (3) use the accelerometer sensor, and (4) have information about the scientific validity. The other functionalities of the mobile application are not included in this study.

Therefore, the study has been performed in the Google Play Store, at 31st July 2017, searching by the following query: "exercise calorie tracker". The data extracted from the mobile applications are the information about the scientific validation, the sensors used, the rating of the user reviews, the number of downloads, the name of the author, and other information about each mobile application.

After the research, illustrated in the Fig. 1, 248 mobile applications are identified, of which 112 mobile applications that do not use sensors, were excluded. The remaining 136 mobile applications were evaluated in terms of the use of the accelerometer sensor, resulting in the exclusion of 16 mobile applications. The verification of the scientific validation of the remaining 120 mobile applications resulted in the exclusion of 114 mobile applications for which the authors do not present information about the scientific support. A total of 6 mobile applications scientifically validated are included in this study. However, some mobile applications that are not validated have thousands or millions of downloads in Google Play Store, which may represent a risk to the users, because these applications may return invalid or inconsistent values.

As verified, only a small set of the mobile applications, around of $2.4 \%$, present some information about the scientific background. Table 1 presents a summary of the characteristics of the mobile applications, which use scientific methods.

This paper focuses on the research of the existent methods to adapt/create a new method for the estima- 


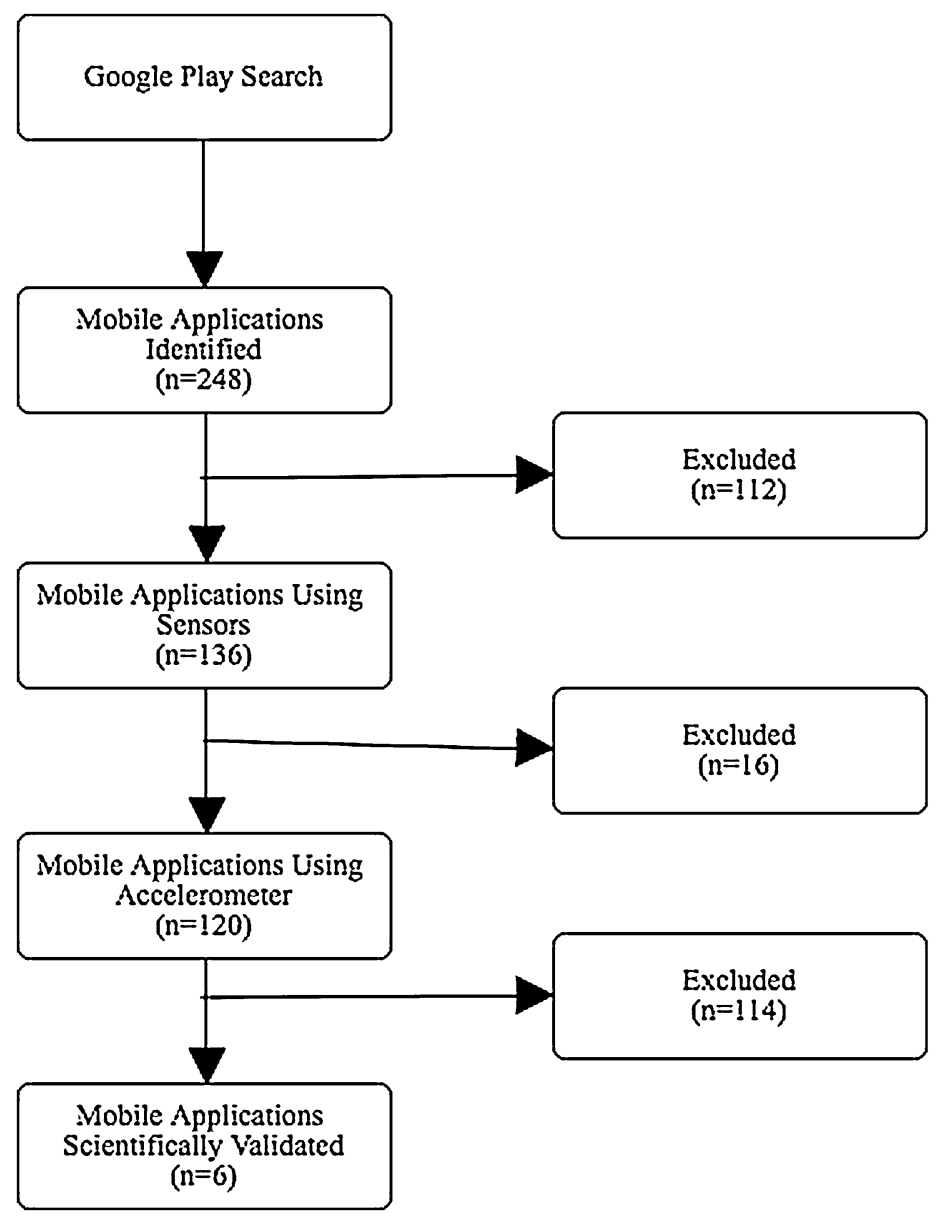

Fig. 1. Flow diagram of identification and exclusion of mobile applications.

tion of the energy expenditure using mobile devices.

The estimation of the energy expenditure based on the data captured by several sensors and/or mobile devices has been subject of research studies, from which different solutions were proposed, including the use of metabolic equivalents of tasks (MET) to measure physical activity of people [15], or statistically validated methods using the accelerometer data from a mobile device [24,25]. These data depend on both the subject and the location. On the one hand, the result is related with the individual characteristics of each person, including the gender, the weight, the height, the age, and the lifestyle $[13,66]$. On the other hand, the result is also a location of environmental factors, e.g. temperature and humidity, culture, and types of food [8].

\subsection{Literature review}

MET is a physiological measure expressing the energy cost of levels of physical activity that is being performed by a person, which may include running, walking or other physical exercises as well as activity performed by a person with sedentary lifestyle. The MET value may be estimated based on the speed and accelerometer data [15], its outputs $(x, y$ and $z)$ representing the acceleration on each of the tri-axial directions, allowing for the calculation of the magnitude of vector (MV) in each instant of the data collection, according the Eq. (1).

$$
\mathrm{MV}=\sqrt{x^{2}+y^{2}+z^{2}}
$$

where MV is the Magnitude of Vector, and $x, y$, and $z$ are the outputs of the accelerometer. 
Table 1

Mobile applications that presents information about the scientific validation

\begin{tabular}{|c|c|c|c|c|c|c|}
\hline Mobile applications & Scientific validation & Sensors & Comments & $\begin{array}{l}\text { User } \\
\text { reviews }\end{array}$ & Number of downloads & Author \\
\hline $\begin{array}{l}\text { Calorie Counter } \\
\text { PRO MyNetDiary } \\
{[49]}\end{array}$ & $\begin{array}{l}\text { The scientific } \\
\text { validation is not } \\
\text { clear, but it has } \\
\text { some information } \\
\text { published in } \\
\text { journals [61] }\end{array}$ & $\begin{array}{l}\text { GPS accelerometer } \\
\text { compass camera }\end{array}$ & $\begin{array}{l}\text { Measures the } \\
\text { number of calories } \\
\text { based on the } \\
\text { number of steps. }\end{array}$ & 4.4 & $1,000,000-5,000,000$ & MyNetDiary.com \\
\hline $\begin{array}{l}\text { 8fit - Workout \& } \\
\text { Meal Plans [1] }\end{array}$ & $\begin{array}{l}\text { The scientific } \\
\text { validation is not } \\
\text { clear, but it has } \\
\text { some information } \\
\text { published in } \\
\text { Websites [2] }\end{array}$ & $\begin{array}{l}\text { GPS accelerometer } \\
\text { compass camera }\end{array}$ & $\begin{array}{l}\text { Measures the } \\
\text { number of calories } \\
\text { based on the } \\
\text { number of steps. }\end{array}$ & 4.5 & $500,000-1,000,000$ & 8 fit \\
\hline $\begin{array}{l}\text { Noom Coach: } \\
\text { Weight Loss Plan } \\
\text { [53] }\end{array}$ & $\begin{array}{l}\text { Scientifically } \\
\text { validated, presented } \\
\text { in several studies } \\
{[55,61]}\end{array}$ & $\begin{array}{l}\text { GPS accelerometer } \\
\text { compass camera }\end{array}$ & $\begin{array}{l}\text { Measures the } \\
\text { number of calories } \\
\text { based on the } \\
\text { accelerometer data. }\end{array}$ & 4.3 & $10,000,000-50,000,000$ & Noom Inc. \\
\hline $\begin{array}{l}\text { Exercise Buddy } \\
{[58]}\end{array}$ & $\begin{array}{l}\text { Scientifically } \\
\text { validated, because } \\
\text { includes scientific } \\
\text { information of } \\
\text { ACSM (American } \\
\text { College of Sports } \\
\text { Medicine) }\end{array}$ & $\begin{array}{l}\text { GPS accelerometer } \\
\text { compass camera }\end{array}$ & $\begin{array}{l}\text { Measures the } \\
\text { number of calories } \\
\text { based on the } \\
\text { accelerometer data. }\end{array}$ & 3.9 & $5,000-10,000$ & PANAGOLA \\
\hline Lark Chat [41] & $\begin{array}{l}\text { Scientifically } \\
\text { validated, because } \\
\text { the company } \\
\text { performs research } \\
\text { studies [51] }\end{array}$ & $\begin{array}{l}\text { GPS accelerometer } \\
\text { compass camera }\end{array}$ & $\begin{array}{l}\text { Measures the } \\
\text { number of calories } \\
\text { based on the sensor } \\
\text { available in the } \\
\text { mobile device. }\end{array}$ & 4.2 & $50,000-100,000$ & Lark \\
\hline $\begin{array}{l}\text { iCountTimer Pro } \\
{[67]}\end{array}$ & $\begin{array}{l}\text { The scientific } \\
\text { validation is not } \\
\text { clear, but it won a } \\
\text { prize [67] }\end{array}$ & $\begin{array}{l}\text { GPS accelerometer } \\
\text { compass camera }\end{array}$ & $\begin{array}{l}\text { Measures the } \\
\text { number of calories } \\
\text { based on the } \\
\text { accelerometer data. }\end{array}$ & 4.6 & $500-1,000$ & RhythmicWorks \\
\hline
\end{tabular}

Thus, the energy expenditure value is determined for each physical activity $[18,19,24,25,27,36,45,50,52,56$, 73] on a time interval manner, instead of the instantaneous energy expenditure method [33].

In line with this, the authors of [72] created a project named TraiNutri, which includes the estimation of a person's energy expenditure, using a mobile device with the Android operating system. This mobile application is named as Activity Level Estimator [34], calculating the energy expenditure based on three activity levels identified by the MV [35]. This mobile application is accurate on average $86 \%$ for different levels of walking and it underestimates the energy expenditure of $23 \%$ during a period of 24 hours [34].

The project named CHIRON [44] aims to monitor congestive heart failure patients using wearable sensors and a smartphone. This system recognizes the physical activity based on machine learning techniques, such as: the linear regression, the Artificial Neural Networks (ANN), e.g., Multi-Layer Perceptron (MLP), the Support vector regression (SVR), the M5P model trees, and the regression trees, which was the best method [44]. The results of this system reports low errors.

On the one hand, in [71] a SVR is used for validating the volume of the oxygen and the carbon dioxide consumption. On the other hand, in the study [81], presented a linear regression model combined with the obtained error related with on the positioning and orientation of the tri-axial accelerometer. This value is determined in accordance with the Eq. (2) and it is based on the sum of the integrals of the absolute value of accelerometer output from all the three measurement directions as input for the measurement of the energy 
expenditure:

$$
\mathrm{EE}=0.104+0.023 \times \mathrm{IAA},
$$

where EE is the Energy Expenditure, IAA is the Integral of Absolute value of Accelerometer.

Several research studies have been performed related to the measurement of energy expenditure, including the development of linear models, neural networks, Random Forest, Support Vector Regression, Context-based methods, based on MET tables, but this study is focused on the use of linear models. However, a generalized analysis of the MET tables is not presented and they are specified for each study. Applying the Eq. (3) for the measurement of the energy expenditure in [17], the MET value is 2.0, when the people is walking slowly, 3.3, when the people is walking fast, and 8.0, when the people is running. When applied to an individual with $56 \mathrm{~kg}$, walking slowly, the value of the correspondent energy expenditure is $1.96 \mathrm{kcal} / \mathrm{min}$.

$$
\begin{aligned}
& \mathrm{EE}\left(\frac{\mathrm{kcal}}{\min }\right) \\
&= 0.0175 \mathrm{kcal} \times \mathrm{kg}^{-1} \times \mathrm{min}^{-1} \\
& \times \mathrm{MET}^{-1} \times \mathrm{MET} \times \text { Weight }(\mathrm{kg}),
\end{aligned}
$$

where EE is the Energy Expenditure, and MET is the value of the metabolic equivalents of tasks.

Depending on the research studies, the model for the measurement of the energy expenditure may be different and adjusted to return values for different time intervals, and the MET value may be estimated based on the speed and accelerometer data as studied by [15]. In $[9,15,42,68]$ is proposed an hourly model for the estimation of the energy expenditure, as presented in the Eq. (4).

$$
\mathrm{EE}\left(\frac{\mathrm{kcal}}{\mathrm{h}}\right)=1.05 \times \operatorname{MET} \times \operatorname{Weight}(\mathrm{kg}),
$$

where EE is the Energy Expenditure, and MET is the value of the metabolic equivalents of tasks.

In [31], the authors presented a linear mixed model, which estimates the oxygen consumption to calculate the energy expenditure during physical activity, considering the height of the subjects. The oxygen consumption was obtained by linear mixed model and the percentages of underestimated results are very low [31]. In [30], the authors proposed an approach of the linear mixed model that implements a procedure to se- lect the fixed-effect variables in the model. Moreover, additional systems for the measurement of the energy expenditure have been developed based on the data provided by the accelerometer sensor $[6,26,39,47,57$, 59,74-76,82].

Finally, the location sensor as the GPS receiver, available on the off-the-shelf mobile device, might be used to evaluate the different intensity of the physical activities combining the speed of travel with the travelled distance [46]. However, this approach is limited when a bike, a train, or a car was used. On the contrary, the energy expenditure, the data collected by the accelerometer may be validated with the relation between the volume of oxygen consumed and the heart rate of each individual. In fact, usually the energy expenditure value provided by the accelerometer is underestimated $[11,12]$. Moreover, other sensors and instruments are used to assess the reliability of the obtained energy expenditure values during the physical activity. Some authors made experiments with the Tritrac accelerometer to estimate the energy expenditure, comparing these values with the data provided by a calorimetry. The value of the energy expenditure obtained by the accelerometer data collected by Tritrac is also considered underestimated [16,37,38,43,70].

The classification of the activities influences the estimation of energy expenditure, and several authors created some methods for the identification of the types of activities. In [60], the authors created a method with linear (regression) and nonlinear (machine-learning-based) models for the estimation of energy expenditure, comparing the accelerometer values with the values obtained with Cosmed K4b2, reporting a correlation of $91 \%$.

The authors of [69] makes use of two artificial neural networks (ANN) to estimate the energy expenditure using accelerometer. The first ANN used consists on the prediction of the energy expenditure using MET, and the second ANN used consists on the identification of the type of activity [69]. The ANN compares the Actigraph data with the accelerometer data, using the distribution of counts (10th, 25th, 50th, 75th, and 90th percentiles of a minute's second-by-second counts) and temporal dynamics of counts (lag, one autocorrelation) as features [69], reporting an accuracy around $88 \%$.

The authors of [20] used several methods for the estimation of the MET value for the correct estimation of the energy expenditure, such as support vector regression (SVR), linear regression (LR), multilayer percep- 
tron (MLP), M5Rules, M5P, and REPTree, reporting an accuracy around $70 \%$.

The work developed in [29] used a soft computing method involving Information Correlation Coefficient analysis and a wrapper feature selection for the extraction of 150 features and was used a Genetic Fuzzy Finite State Machine to reduce to 20 features for the estimation of the energy expenditure.

In [32] was explored deep, convolutional and recurrent neural network approaches to test the performance of deep learning approaches on three different datasets that contain movement data. The authors of [32] recommended convolutional networks for macro gait detection, avoiding the better measurement of energy expenditure.

In [28], the authors compared 5 machine learning algorithms on 4 datasets containing laboratory and simulated free-living activities, improving the measurement of energy expenditure.

In conclusion, other studies presents the use of machine learning algorithms for the estimation of the energy expenditure using accelerometer data, reporting reliable results with this type of methods $[4,10,14$, $21,48,80,83$ ], including k-Nearest Neigbour (k-NN), Deep Leaning, and others.

\section{Proposed method}

This paper explores the method created.previously validated in studies $[24,25]$, in which the value of the energy expenditure is around $300 \mathrm{kcal} / \mathrm{h}$ during running. The study [25] involved 57 young and adult people, which were 43 male and 14 female $(24.37 \pm 5.96$ years) submitted to a protocol on increasing treadmill velocities with four levels (Level 1: $5.8 \mathrm{~km} / \mathrm{h}$; Level 2: $8.4 \mathrm{~km} / \mathrm{h}$; Level 3: $10.3 \mathrm{~km} / \mathrm{h}$; Level 4: $11.6 \mathrm{~km} / \mathrm{h}$ for men and Level 1: $5.1 \mathrm{~km} / \mathrm{h}$; Level 2: $7.7 \mathrm{~km} / \mathrm{h}$; Level 3: $9.0 \mathrm{~km} / \mathrm{h}$ and; Level 4: $10.3 \mathrm{~km} / \mathrm{h}$ for women), each five minutes long [24]. The experimental installation consists of a tri-axial accelerometer connected to the acquisition system, bioPlux, for the acquisition data and a golden standard device, Cosmed K4b2.

For the creation of the model [25], several studies were performed for the calculation of energy expenditure to find an method statistically valid related to the use of the accelerometry data as presented in Eq. (5).

$$
\mathrm{EE}\left(\frac{\mathrm{kcal}}{\mathrm{h}}\right)=0.031 \mathrm{MV}+74.65
$$

where EE is the Energy Expenditure, and MV is the Magnitude of Vector.

Also in this work an electromyography sensor has been used to minimize the error which resulted in the model presented in the Eq. (6); however, this model was not used in this research, because the mobile devices do not include the electromyography sensor:

$$
\begin{aligned}
\operatorname{EE}\left(\frac{\mathrm{kcal}}{\mathrm{h}}\right)= & 58.8496+0.0299 \mathrm{MV} \\
& +0.0437 \mathrm{RMSemg}
\end{aligned}
$$

where EE is the Energy Expenditure, MV is the Magnitude of Vector, and RMSemg is the Root-MeanSquare of Electromiography (EMG).

The measurement of the energy expenditure may be performed using the sensors available in and off-theshelf mobile device, and this study consists in the presentation the analysis for the creation of a validated method studied in [63], which is used for the measurement of the energy expenditure during physical activities. Figure 2 presents the module for the estimation of energy expenditure of the system presented in [63]. The mobile application, presented in the Fig. 1, measures the distance travelled and energy expenditure using a mobile device. It allows the user to define goals for him/her personal daily training, using the validated method.

After the adjustment of the units of the data collected by the sensors connected do the bioPlux research device and the sensors of mobile device, it is possible to estimate the energy expenditure with a mobile device.

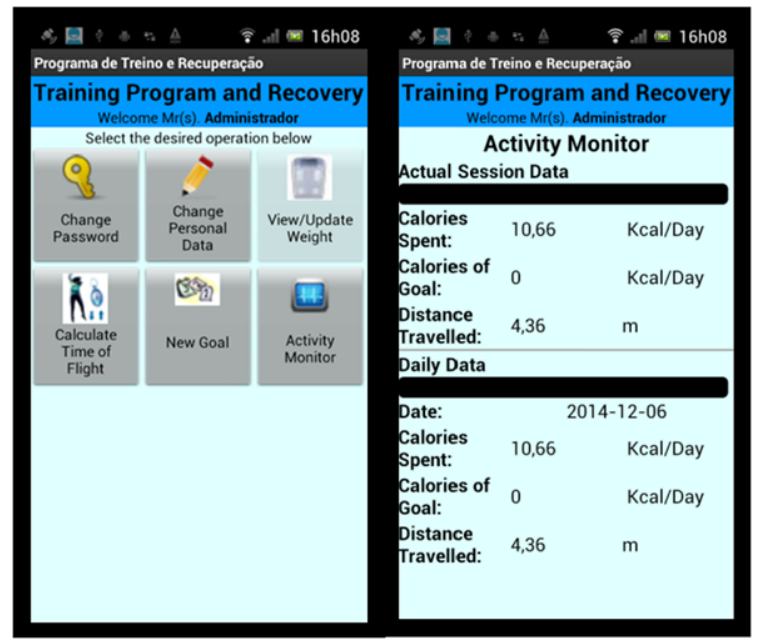

Fig. 2. Mobile application sample screenshots. 
The values of energy expenditure measured by the model represented in the Eq. (5) are obtained in kilocalories per hour $(\mathrm{kcal} / \mathrm{h})$.

The proposed model are able to calculate the energy expenditure during a time interval, receiving the mean of the MV, obtained from the outputs $(\mathrm{X}, \mathrm{Y}, \mathrm{Z})$ provided by the accelerometer. The data obtained from the outputs of the tri-axial accelerometer connected to the bioPlux are in millivolts ( $\mathrm{mV}$ ).

On the other hand, the data obtained from the accelerometer of the mobile device are in different units, while the output values of the accelerometer attached to the bioPlux are obtained in millivolts $(\mathrm{mV})$, the values from the outputs of the accelerometer of the mobile device are in meters per second squared $\left(\mathrm{m} / \mathrm{s}^{2}\right)$.

During the data acquisition, invalid or noised values may be received, but the effects of these values may be minimized with the reducion of real gravity values, obtained by the gravity sensor. Thus, the model developed with the sensors connected to the bioPlux needs to be adapted. The method to adapt the models starts with the calculation of $1 \mathrm{G}$ value of the accelerometer connected, reducing the maximum value obtained with the experiment in various axes that was 1528.01734 mV, obtained the presented Eq. (7).

$$
\begin{aligned}
\mathrm{EE}\left(\frac{\mathrm{kcal}}{\mathrm{h}}\right)= & 0.031 \times(\mathrm{MV}+1528.01734) \\
& +74.65,
\end{aligned}
$$

where EE is the Energy Expenditure, and MV is the Magnitude of Vector.

The Eq. (7) was adapted to receive the accelerometer data without gravity, but the different sources (accelerometer connected to the bioPlux and accelerometer from mobile device) have different units. Assuming the value of the Earth's gravity is equal to $9.81 \mathrm{~m} / \mathrm{s}^{2}$, is possible to convert the units of data, with the method presented in the Eq. (8).

$$
1 \mathrm{~m} / \mathrm{s}^{2}=\frac{1528.01734}{9.81} \mathrm{mV} .
$$

This conversion should be applied to the MV presented in the Eq. (8), obtaining the Eq. (9), in which the magnitude of vector is received in $\mathrm{m} / \mathrm{s}^{2}$ (units obtained by the accelerometer sensor of the mobile device):

$$
\mathrm{EE}\left(\frac{\mathrm{kcal}}{\mathrm{h}}\right)=4.83 \mathrm{MV}+122.02,
$$

where EE is the Energy Expenditure, and MV is the Magnitude of Vector.
For the mobile application developed, the value of the energy expenditure, during a time interval performing physical activity, should be presented to the user. Thus, the value of energy expenditure, measured in background by the mobile application, should be updated to the user's interface around every 10 milliseconds. This time depends on the frequency of the data collection, which is related to the processing capacity of the mobile device.

Due to the fact that the frequency of the accelerometer depends on the mobile device, this study attempts to capture the sensors' data as fastest as possible [40]. As verified with the experiments during this research, this method allows the mobile device to get data every around 10 milliseconds.

Thus, the timing of the Eq. (9) should be adapted to the minimum unit of time, which is the second. This adaptation is presented in the Eq. (10).

$$
\mathrm{EE}\left(\frac{\mathrm{kcal}}{\mathrm{s}}\right)=\frac{4.83 \mathrm{MV}+122.02}{3600},
$$

where EE is the Energy Expenditure, and MV is the Magnitude of Vector.

\section{Method validation}

The method created in this study was tested in healthy people aged between 12 and 60 years old. For the validation of the developed method, the accelerometer data was acquired with a mobile application that saves the raw data in text files, which are available at [5]. The accelerometer data is automatically acquired by the developed mobile application, which acquires 5 seconds of data every 5 minutes in order to measure the EE with different level intensities and different phases of the performance of the activities, which is affected by several constraints, e.g., fatigue level of the individual and intensity of the activity performed. During the experiments of the method created, the people performed several activities, such as standing, gym (walking), climbing stairs, walking, jumping, running, playing tennis, and squatting, with a mobile device on the waist, handling the capture of the accelerometer signal during the execution of the activities. The choose of these activities were important for the comparison of the values obtained by other methods (i.e., Cosmed [24,25], and Felizardo et al. [24,25]) in order to validate the reliability of the proposed method. The method developed includes the measurement of 
Table 2

Mean \pm standard deviation values of the Magnitude of Vectors (MV) and Energy Expenditure (EE) for the activities

\begin{tabular}{lccc}
\hline Activities & MV & EE $(\mathrm{kcal} / \mathrm{s})$ & EE $(\mathrm{kcal} / \mathrm{h})$ \\
\hline Standing & $0.226 \pm 0.221$ & $0.034 \pm 0.0003$ & $123.1 \pm 1.066$ \\
Gym & $0.657 \pm 0.407$ & $0.035 \pm 0.0005$ & $125 \pm 1.967$ \\
Walking & $0.541 \pm 0.242$ & $0.035 \pm 0.0003$ & $124.6 \pm 1.168$ \\
Downstairs & $0.82 \pm 0.905$ & $0.035 \pm 0.001$ & $126 \pm 4.37$ \\
Upstairs & $0.167 \pm 0.585$ & $0.034 \pm 0.0007$ & $122.8 \pm 2.823$ \\
Jumping & $0.21 \pm 0.768$ & $0.034 \pm 0.001$ & $123 \pm 3.707$ \\
Running & $5.724 \pm 2.286$ & $0.042 \pm 0.0003$ & $149.7 \pm 11.042$ \\
Playing tennis & $1.828 \pm 2.268$ & $0.036 \pm 0.003$ & $130.9 \pm 10.954$ \\
\hline
\end{tabular}

the MV of the accelerometer data, and the creation and application a new method based on Felizardo et al. [24,25]. For MV and EE calculation was used fifteen datasets, randomly selected from the data acquired, for each activity, and the results are presented in Table 2.

\section{Results}

After the data acquisition during the experiments, the processing of the data was performed, obtaining the results presented in the Table 2, presenting the mean \pm standard deviation values of the size of magnitude of vector (MV) and the amount of energy expenditure (EE) obtained during the performance of the activities, verifying that a correlation between the mean of $\mathrm{MV}$ and the EE does not exists, because the EE depends on the movement along the acquisition time, and only in running activity the EE significantly increases, and the EE for other activities is around $120 \mathrm{kcal} / \mathrm{h}$. In Fig. 3(a) and (b), the mean values of MV and EE are presented, verifying that high values of the mean values of MV, increases the EE less than expected, be-

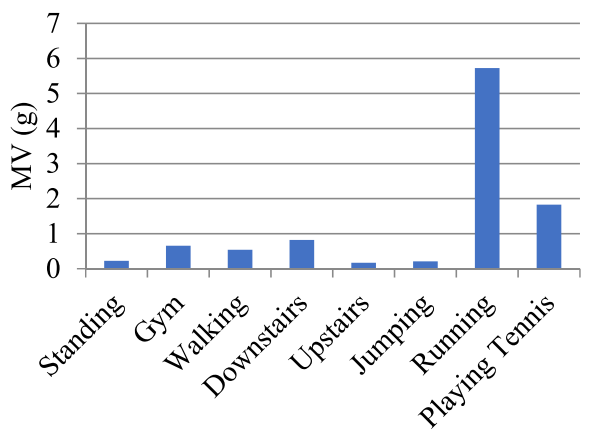

a) cause, during the acquisition time, the movement intensity fluctuates.

In conclusion, the mean of size of magnitude of vector is not directly correspondent to the amount of energy expenditure, because the energy expenditure is calculated for a defined time slot and the size of the magnitude of vector during the time slot can be higher than a mean of the magnitude of vectors during all time of activity. As example, the jumping does not have a constant size of magnitude of vector and the energy expenditure calculated is lower than the real energy expenditure.

\section{Discussion}

This study is based on the method created in [25], adapting this method to allow the implementation in a mobile application, using the mobile device's sensors. It includes the estimation of $1 \mathrm{G}$ value of the accelerometer connected to the bioPlux device for the adaptation of the units of the MV, which allow the use of the values captured by the accelerometer of the mobile device with this method.

As verified during this study, only 6 mobile applications for the estimation of the energy expenditure available on Google Play Store includes information about the scientific validity of the mobile applications. The purpose of this study consists on the creation of a validated mobile application for the estimation of the energy expenditure.

However, this study has limitations in the tests of the mobile application developed, because it should be validated with data acquired from the golden standard device, Cosmed K4b2, used in [24,25].

The study [25] analyses the energy expenditure in 4 levels of activity different by gender. For man, the ac-

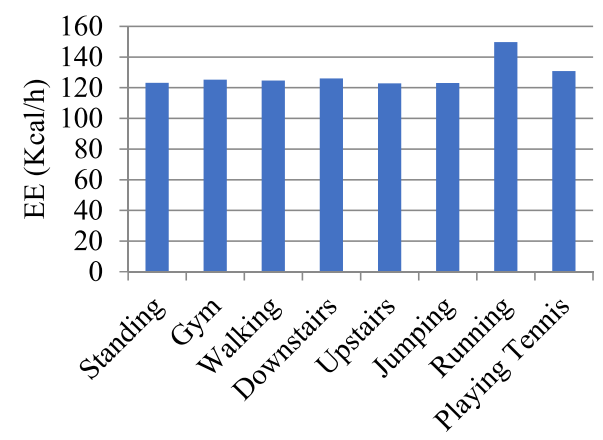

b)

Fig. 3. Comparison of Magnitude of Vectors (MV) (a) and Energy Expenditure (EE) (b) for the activities. 
Table 3

Energy expenditure obtained with our proposed model and original model

\begin{tabular}{llc}
\hline Activity & \multicolumn{1}{c}{ Method } & EE $(\mathrm{kcal} / \mathrm{h})$ \\
\hline Walking & Proposed method & 124.6 \\
$(5-6 \mathrm{~km} / \mathrm{h})$ & Cosmed [24,25] & 87.3 \\
& Felizardo et al. [24,25] & 106.8 \\
Running & Proposed method & 149.7 \\
$(10-11 \mathrm{~km} / \mathrm{h})$ & Cosmed [24,25] & 188.9 \\
& Felizardo et al. [24,25] & 172.6 \\
\hline
\end{tabular}

tivities are walking $(5.8 \mathrm{~km} / \mathrm{h})$ and running $(8.4 \mathrm{~km} / \mathrm{h}$, $10.3 \mathrm{~km} / \mathrm{h}$, and $11.6 \mathrm{~km} / \mathrm{h}$ ). For woman, the activities are walking $(5.1 \mathrm{~km} / \mathrm{h})$ and running $(7.7 \mathrm{~km} / \mathrm{h}, 9 \mathrm{~km} / \mathrm{h}$, and $10.3 \mathrm{~km} / \mathrm{h}$ ). On the other hand, the activities of this study are standing, gym (walking), climbing stairs, walking, jumping, running, playing tennis, and squatting.

Thus, the results of this study are limited to the adaptation of the method previously validated in [25], supposing that the results are valid, because it use a validated method. As presented in the Table 3, the values related to energy expenditure obtained for walking activity with the proposed method are higher than the method developed by Felizardo et al. [24,25]. However, for the running activity, the results of energy expenditure obtained are lower than the values obtained by the method developed by Felizardo et al. [24,25].

\section{Conclusions}

The creation of a validated method for the measurement of energy expenditure during physical activities capable for the implementation in a mobile application is an important issue for increase the confidence of the mobile applications in the market. Only a few set of mobile applications has information about the validity of the methods implemented in the mobile application currently in the market, which are used for thousands of individuals. These mobile application are especially important for support a training program.

This study concludes with a successfully adaptation of the method previously created in [25]. The detailed information about this study is presented in the [63]. For more information or access to the data of this research, it is available at the ALLab (Assisted Living Computing and Telecommunications laboratory) MediaWiki [3], where the research was conducted, and the mobile application and the web platform to support this research are available at [62].

\section{Acknowledgements}

This work was supported by FCT project PEstOE/EEI/L A0008/2013 (Este trabalho foi suportado pelo projecto FCT PEst-OE/EEI/LA0008/2013).

The authors would also like to acknowledge the contribution of the COST Action IC1303 - AAPELE Architectures, Algorithms and Protocols for Enhanced Living Environments.

\section{References}

[1] 8fit, 8fit - workout \& meal plans - Android Apps on Google play, available at: https://play.google.com/store/apps/details? id=com.eightfit.app. Accessed September 24th, 2017.

[2] 8fit, Mobile workouts, meal plans and personal trainer, available at: https://8fit.com/. Accessed September 24th, 2017.

[3] A. Signals, Main Page - ALLab Signals, available at: http:// allab.di.ubi.pt/mediawiki/, Accessed September 24th, 2017.

[4] F. Albinali, S. Intille, W. Haskell and M. Rosenberger, Using wearable activity type detection to improve physical activity energy expenditure estimation, in: Proceedings of the 12th ACM International Conference on Ubiquitous Computing, ACM, Copenhagen, Denmark, 2010, pp. 311-320. doi:10. 1145/1864349.1864396.

[5] ALLab, August 2017 - Multi-sensor data fusion in mobile devices for the identification of activities of daily living - ALLab Signals, available at: https://allab.di.ubi.pt/mediawiki/index. php/August_2017-_Multi-sensor_data_fusion_in_mobile_ devices_for_the_identification_of_activities_of_daily_living. Accessed September 2nd, 2017.

[6] P. Anastasopoulou, M. Tansella, J. Stumpp, L. Shammas and S. Hey, Classification of human physical activity and energy expenditure estimation by accelerometry and barometry, in: Engineering in Medicine and Biology Society (EMBC), 2012 Annual International Conference of the IEEE, IEEE, 2012, pp. 6451-6454. doi:10.1109/EMBC.2012.6347471.

[7] Apple, App Store, available at: https://www.apple.com/ios/ app-store/, Accessed September 24th, 2017.

[8] F.K. Assah, U. Ekelund, S. Brage, K. Corder, A. Wright, J.C. Mbanya and N.J. Wareham, Predicting physical activity energy expenditure using accelerometry in adults from subSahara Africa, Obesity 17 (2009), 1588-1595. doi:10.1038/ oby.2009.39.

[9] H. Badawi, M. Eid and A. El Saddik, Diet advisory system for children using biofeedback sensor, in: Medical Measurements and Applications Proceedings (MeMeA), 2012 IEEE International Symposium on, IEEE, 2012, pp. 1-4.

[10] A.G. Bonomi, G. Plasqui, A.H. Goris and K.R. Westerterp, Improving assessment of daily energy expenditure by identifying types of physical activity with a single accelerometer, J Appl Physiol 107 (2009), 655. doi:10.1152/japplphysiol. 00150.2009.

[11] D.R. Bouchard and F. Trudeau, Estimation of energy expenditure in a work environment: Comparison of accelerometry and oxygen consumption/heart rate regression, Ergonomics $\mathbf{5 1}$ (2008), 663-670. doi:10.1080/00140130701780484. 
[12] C.V. Bouten, K.R. Westerterp, M. Verduin and J.D. Janssen, Assessment of energy-expenditure for physical-activity using a triaxial accelerometer, Medicine and Science in Sports and Exercise 26 (1994), 1516-1523.

[13] I.d. Carmo, Saber Emagrecer, booklet, Lisboa, 2002.

[14] S. Carneiro, J. Silva, B. Aguiar, T. Rocha, I. Sousa, T. Montanha and J. Ribeiro, Accelerometer-based methods for energy expenditure using the smartphone, in: 2015 IEEE International Symposium on Medical Measurements and Applications (MeMeA) Proceedings, 2015, pp. 151-156. doi:10.1109/ MeMeA.2015.7145190.

[15] S. Carneiro, J. Silva, B. Aguiar, T. Rocha, I. Sousa, T. Montanha and J. Ribeiro, Accelerometer-based methods for energy expenditure using the smartphone, in: Medical Measurements and Applications (MeMeA), 2015 IEEE International Symposium on, IEEE, 2015, pp. 151-156. doi:10.1109/MeMeA.2015. 7145190.

[16] K.Y. Chen and M. Sun, Improving energy expenditure estimation by using a triaxial accelerometer, Journal of Applied Physiology 83 (1997), 2112-2122. doi:10.1152/jappl.1997.83. 6.2112 .

[17] S.-H. Choi, Estimation of activity energy expenditure according to the position of user's smart phone, in: Information Science and Security (ICISS), 2015 2nd International Conference on, IEEE, 2015, pp. 1-4.

[18] S.E. Crouter, J.R. Churilla and D.R. Bassett Jr., Estimating energy expenditure using accelerometers, Eur J Appl Physiol 98 (2006), 601. doi:10.1007/s00421-006-0307-5.

[19] S.E. Crouter, K.G. Clowers and D.R. Bassett, A novel method for using accelerometer data to predict energy expenditure, Journal of Applied Physiology 100 (2006), 1324-1331. doi:10. 1152/japplphysiol.00818.2005.

[20] B. Cvetković, B. Kaluža, R. Milić and M. Luštrek, Towards human energy expenditure estimation using smart phone inertial sensors, in: Ambient Intelligence: 4th International Joint Conference, AmI 2013, Proceedings, Dublin, Ireland, December 3-5, 2013, J.C. Augusto, R. Wichert, R. Collier, D. Keyson, A.A. Salah and A.-H. Tan, eds, Springer International Publishing, Cham, 2013, pp. 94-108

[21] B. Cvetković, R. Szeklicki, V. Janko, P. Lutomski and M. Luštrek, Real-time activity monitoring with a wristband and a smartphone, Information Fusion (2017). doi:10.1016/j.inffus. 2017.05.004

[22] D. Dubey, A. Amritphale, A. Sawhney, N. Amritphale, P. Dubey and A. Pandey, Smart phone applications as a source of information on stroke, J Stroke 16 (2014), 86-90. doi:10. 5853/jos.2014.16.2.86.

[23] eMarketer, Mobile phone, Smartphone usage varies globally, https://www.emarketer.com/Article/ Mobile-Phone-Smartphone-Usage-Varies-Globally/1014738, [Accessed March 3rd, 2017], 2016.

[24] V. Felizardo, P.D. Gaspar, N.M. Garcia and V. Reis, Acquisition of multiple physiological parameters during physical exercise, International Journal of E-Health and Medical Communications 2 (2011), 37-49. doi:10.4018/jehmc.2011100103.

[25] V.d.S. Felizardo, Validação do acelerómetro xyzPlux para estimação do Gasto Energético com aquisição de diversos parâmetros fisiológicos, Mestre em Engenharia Electrotécnica e de Computadores, Universidade da Beira Interior, 2010.
[26] E. Fortune, M. Tierney, C.N. Scanaill, A. Bourke, N. Kennedy and J. Nelson, Activity level classification algorithm using SHIMMER ${ }^{\mathrm{TM}}$ wearable sensors for individuals with rheumatoid arthritis, in: Engineering in Medicine and Biology Society, EMBC, 2011 Annual International Conference of the IEEE, IEEE, 2011, pp. 3059-3062. doi:10.1109/IEMBS.2011. 6090836.

[27] N. Garatachea, G.T. Luque and J.G. Gallego, Physical activity and energy expenditure measurements using accelerometers in older adults, Nutricion Hospitalaria 25 (2010), 224-230. doi:10.3305/Nh.2010.25.2.4439.

[28] M. Gjoreski, H. Gjoreski, M. Lustrek and M. Gams, How accurately can your wrist device recognize daily activities and detect falls?, Sensors (Basel) 16 (2016). doi:10.3390/s16060800.

[29] S. González, J. Sedano, J.R. Villar, E. Corchado, Á. Herrero and B. Baruque, Features and models for human activity recognition, Neurocomputing 167 (2015), 52-60. doi:10.1016/ j.neucom.2015.01.082.

[30] E. Haapalainen, P. Laurinen, J. Roning and H. Kinnunen, Estimation of exercise energy expenditure using a wrist-worn accelerometer: A linear mixed model approach with fixed-effect variable selection, in: Machine Learning and Applications, 2008. ICMLA'08. Seventh International Conference on, IEEE, 2008, pp. 796-801. doi:10.1109/ICMLA.2008.131.

[31] E. Haapalainen, P. Laurinen, P. Siirtola, J. Röning, H. Kinnunen and H. Jurvelin, Exercise energy expenditure estimation based on acceleration data using the linear mixed model, in: Information Reuse and Integration, IRI 2008, IEEE International Conference on, IEEE, 2008, pp. 131-136.

[32] N.Y. Hammerla, S. Halloran and T. Ploetz, Deep, convolutional, and recurrent models for human activity recognition using wearables, in: Proceedings of the Twenty-Fifth International Joint Conference on Artificial Intelligence, AAAI Press, New York, New York, USA, 2016, pp. 1533-1540.

[33] S. Härtel, J.-P. Gnam, S. Löffler and K. Bös, Estimation of energy expenditure using accelerometers and activity-based energy models - validation of a new device, European Review of Aging and Physical Activity 8 (2010), 109-114. doi:10.1007/ s11556-010-0074-5.

[34] J. Hausmann, Activity Level Estimator, Master of Science degree in Information Systems, University of Geneva, 2010.

[35] P. Hendrick, M.L. Bell, P.J. Bagge and S. Milosavljevic, Can accelerometry be used to discriminate levels of activity?, Ergonomics 52 (2009), 1019-1025. doi:10.1080/ 00140130902846464.

[36] J. Hyun Choi, J. Lee, H. Tai Hwang, J. Pal Kim, J.C. Park and K. Shin, Estimation of activity energy expenditure: Accelerometer approach, Conf Proc IEEE Eng Med Biol Soc 4 (2005), 3830-3833. doi:10.1109/IEMBS.2005.1615295.

[37] P.M.V. Ilha, R.C.R.d. Silva and E.L. Petroski, Validade do Acelerômetro Tri-axial TRITRAC: Um Estudo de Revisão, Rev. Bras. Cine. Des. Hum. 7 (2005), 75-81.

[38] D. Jacobi, A.E. Perrin, N. Grosman, M.F. Dore, S. Normand, J.M. Oppert and C. Simon, Physical activity-related energy expenditure with the RT3 and TriTrac accelerometers in overweight adults, Obesity (Silver Spring) 15 (2007), 950-956. doi:10.1038/oby.2007.605.

[39] D. Kim and H.C. Kim, Activity energy expenditure assessment system based on activity classification using multi-site triaxial accelerometers, IEEE engineering in medicine and biology magazine 1 (2007), 2285. 
[40] S. Komatineni, D. MacLean and S.Y. Hashimi, Pro Android 3, Apress, United States of America, 2011.

[41] Lark, Lark chat - Android Apps on Google play, available at: https://play.google.com/store/apps/details?id=com.lark. meadowlark2, Accessed September 24th, 2017.

[42] M.-W. Lee, A.M. Khan, J.-H. Kim, Y.-S. Cho and T.-S. Kim, A single tri-axial accelerometer-based real-time personal life $\log$ system capable of activity classification and exercise information generation, in: Engineering in Medicine and Biology Society (EMBC), 2010 Annual International Conference of the IEEE, IEEE, 2010, pp. 1390-1393.

[43] N.Y. Leenders, W.M. Sherman and H.N. Nagaraja, Energy expenditure estimated by accelerometry and doubly labeled water: Do they agree?, Med Sci Sports Exerc 38 (2006), 21652172. doi:10.1249/01.mss.0000235883.94357.95.

[44] M. Luštrek, B. Cvetković and S. Kozina, Energy expenditure estimation with wearable accelerometers, in: Circuits and Systems (ISCAS), 2012 IEEE International Symposium on, IEEE, 2012, pp. 5-8. doi:10.1109/ISCAS.2012.6271906.

[45] A.M. Machado-Rodrigues, E.S.M.J. Coelho, J. Mota, E. Cyrino, S.P. Cumming, C. Riddoch, G. Beunen and R.M. Malina, Agreement in activity energy expenditure assessed by accelerometer and self-report in adolescents: Variation by sex, age, and weight status, J Sports Sci 29 (2011), 1503-1514. doi:10.1080/02640414.2011.593185.

[46] R. Maddison and C. Ni Mhurchu, Global positioning system: A new opportunity in physical activity measurement, International Journal of Behavioral Nutrition and Physical Activity 6 (2009), 1-8. doi:10.1186/1479-5868-6-73.

[47] B. Mortazavi, M. Pourhomayoun, H. Ghasemzadeh, R. Jafari, C.K. Roberts and M. Sarrafzadeh, Context-aware data processing to enhance quality of measurements in wireless health systems: An application to MET calculation of exergaming actions, Internet of Things Journal, IEEE 2 (2015), 84-93. doi:10.1109/JIOT.2014.2364407.

[48] E. Munguia Tapia, Using machine learning for real-time activity recognition and estimation of energy expenditure, Ph.D. dissertation, Massachusetts Institute of Technology, 2008.

[49] MyNetD, Calorie counter PRO MyNetDiary - Android Apps on Google play, available at: https://play.google.com/ store/apps/details?id=com.fourtechnologies.mynetdiary.ad, Accessed September 24th, 2017.

[50] J. Neville, A. Wixted, D. Rowlands and D. James, Accelerometers: An underutilized resource in sports monitoring, in: $I n$ telligent Sensors, Sensor Networks and Information Processing (ISSNIP), 2010 Sixth International Conference on, IEEE, Brisbane, QLD, 2010, pp. 287-290. doi:10.1109/ISSNIP.2010. 5706766.

[51] M.P.R. Newswire, Meet your new diet BFF: Lark chat transforms your apple watch into your personal weight loss \& fitness coach, available at: http://www.multivu.com/players/ English/7512151-lark-chat-weight-loss-app/, [Accessed September 24th, 2017], 2012.

[52] A. Nilsson, S. Brage, C. Riddoch, S.A. Anderssen, L.B. Sardinha, N. Wedderkopp, L.B. Andersen and U. Ekelund, Comparison of equations for predicting energy expenditure from accelerometer counts in children, Scand $J$ Med Sci Sports 18 (2008), 643-650. doi:10.1111/j.1600-0838. 2007.00694.x.
[53] Noom, Noom coach: Weight loss plan - Android Apps on Google play, available at: https://play.google.com/store/apps/ details?id=com.wsl.noom, Accessed September 24th, 2017.

[54] O. Smartphone, Market Share, 2015 Q2, available at: http:// www.idc.com/prodserv/smartphone-os-market-share.jsp, [Accessed 10th January, 2016], 2015.

[55] S. Pagoto, K. Schneider, M. Jojic, M. DeBiasse and D. Mann, Evidence-based strategies in weight-loss mobile apps, American Journal of Preventive Medicine 45 (2013), 576-582. doi:10.1016/j.amepre.2013.04.025.

[56] S. Palma, H. Silva, H. Gamboa and P. Mil-Homens, Standing jump loft time measurement - an acceleration based method, in: Biosignals 2008: Proceedings of the First International Conference on Bio-Inspired Systems and Signal Processing, Vol II, 2008, pp. 393-396.

[57] A. Panagiota, S. Layal and H. Stefan, Assessment of human gait speed and energy expenditure using a single triaxial accelerometer, in: Wearable and Implantable Body Sensor Networks (BSN), 2012 Ninth International Conference on, IEEE, 2012, pp. 184-188. doi:10.1109/BSN.2012.7.

[58] Panagola, Exercise buddy - Android Apps on Google play, available at: https://play.google.com/store/apps/details? id=com.panagola.app.exercisebuddy, Accessed September 24th, 2017.

[59] A. Pande, G. Casazza, A. Nicorici, E. Seto, S. Miyamoto, M. Lange, T. Abresch, P. Mohapatra and J. Han, Energy expenditure estimation in boys with duchene muscular dystrophy using accelerometer and heart rate sensors, in: Healthcare Innovation Conference (HIC), 2014 IEEE, IEEE, 2014, pp. 26-29. doi:10.1109/HIC.2014.7038866.

[60] A. Pande, P. Mohapatra, A. Nicorici and J.J. Han, Machine learning to improve energy expenditure estimation in children with disabilities: A pilot study in duchenne muscular dystrophy, JMIR Rehabil Assist Technol 3 (2016), e7. doi:10.2196/ rehab.4340.

[61] R. Patel, L. Sulzberger, G. Li, J. Mair, H. Morley, M. Shing and $\mathrm{N}$. Wilson, Smartphone apps for weight loss and smoking cessation: Quality ranking of 120 apps, The New Zealand Medical Journal 128 (2015), 73-76.

[62] I. Pires, Programa de Treino e Recuperação::, available at: http://trainingprogram.impires.pt/, Accessed September 24th, 2017.

[63] I.M.S. Pires, Aplicação móvel e plataforma Web para suporte à estimação do gasto energético em atividade física, Master's Thesis, University of Beira, 2012, available at: http:// ubibliorum.ubi.pt/bitstream/10400.6/3721/1/dissertacao_ IvanPires.pdf.

[64] Play.google.com, Google Play, available at: https://play. google.com/store, [Accessed September 24th, 2017], 2017.

[65] N. Pombo, N. Garcia, K. Bousson and V. Felizardo, Artificial neural learning based on big data process for eHealth applications, in: Artificial Intelligence Technologies and the Evolution of Web 3.0, 2015, p. 291. doi:10.4018/978-1-4666-81477.ch014.

[66] F. Póvoas, O Prazer de Emagracer, Caderno, Alfragide, 2010.

[67] RhythmicWorks, ICountTimer pro - Android Apps on Google play, available at: https://play.google.com/store/apps/details? id=com.icounttimer.android, Accessed September 24th, 2017.

[68] N. Ryu, Y. Kawahawa and T. Asami, A calorie count application for a mobile phone based on METS value, in: 2008 5th 
Annual IEEE Communications Society Conference on Sensor, Mesh and Ad Hoc Communications and Networks, 2008.

[69] J. Staudenmayer, D. Pober, S. Crouter, D. Bassett and P. Freedson, An artificial neural network to estimate physical activity energy expenditure and identify physical activity type from an accelerometer, J Appl Physiol 107 (2009), 1300-1307. doi:10. 1152/japplphysiol.00465.2009.

[70] B.G. Steele, L. Holt, B. Belza, S. Ferris, S. Lakshminaryan and D.M. Buchner, Quantitating physical activity in COPD using a triaxial accelerometer, Chest 117 (2000), 1359-1367. doi:10. 1378/chest.117.5.1359.

[71] S. Su, L. Wang, B. Celler, A. Savkin and E. Ambikairajah, Estimation of walking energy expenditure by using support vector regression, in: IEEE Engineering in Medicine and Biology Society Annual Conference, IEEE, 2005.

[72] TRAINUTRI, TRAINUTRI AAL-2009-2-129| AAL-0100002010-3 | TRAINing and NUTRItion senior social platform TraiNutri, available at: http://www.trainutri.com/, [Accessed September 24th, 2017], 2011

[73] R.P. Troiano, Translating accelerometer counts into energy expenditure: Advancing the quest, Journal of Applied Physiology 100 (2006), 1107-1108. doi:10.1152/japplphysiol.01577. 2005.

[74] N. Twomey, S. Faul and W.P. Marnane, Comparison of accelerometer-based energy expenditure estimation algorithms, in: Pervasive Computing Technologies for Healthcare (PervasiveHealth), 2010 4th International Conference On-NO PERMISSIONS, IEEE, 2010, pp. 1-8.

[75] H. Vathsangam, E.T. Schroeder and G. Sukhatme, Hierarchical approaches to estimate energy expenditure using phonebased accelerometers, Biomedical and Health Informatics, IEEE Journal of 18 (2014), 1242-1252. doi:10.1109/JBHI. 2013.2297055.

[76] M. Voleno, S.J. Redmond, S. Cerutti and N.H. Lovell, Energy expenditure estimation using triaxial accelerometry and barometric pressure measurement, in: Engineering in Medicine and
Biology Society (EMBC), 2010 Annual International Conference of the IEEE, IEEE, 2010, pp. 5185-5188. doi:10.1109/ IEMBS.2010.5626271

[77] W.H. Organization, Global Recommendations on Physical Activity for Health - 5-17 years old, available at: http://www.who.int/dietphysicalactivity/ physical-activity-recommendations-5-17years.pdf, [Accessed September 24th, 2017], 2011.

[78] W.H. Organization, Global Recommendations on Physical Activity for Health - 18-64 years old, http://www.who.int/dietphysicalactivity/ physical-activity-recommendations-18-64years.pdf, [Accessed September 24th, 2017], 2011.

[79] W.H. Organization, Global Recommendations on Physical Activity for Health $->65$ years old, available at: http://www.who.int/dietphysicalactivity/ physical-activity-recommendations-65years.pdf, [Accessed September 24th, 2017], 2011.

[80] C. Wang, M. Li, J. Zhang and Y. Xu, A model with hierarchical classifiers for activity recognition on mobile devices, in: 2016 IEEE Trustcom/BigDataSE/ISPA, 2016, pp. 1295-1301. doi:10.1109/TrustCom.2016.0207.

[81] L. Wang, S. Su, B. Celler and E. Ambikairajah, Analysis of orientation error of triaxial accelerometers on the assessment of energy expenditure, in: IEEE Engineering in Medicine and Biology Society Annual Conference, 2005.

[82] A.J. Wixted, D.V. Thiel, A.G. Hahn, C.J. Gore, D.B. Pyne and D.A. James, Measurement of energy expenditure in elite athletes using MEMS-based triaxial accelerometers, Sensors Journal, IEEE 7 (2007), 481-488. doi:10.1109/JSEN.2007. 891947.

[83] J. Zhu, A. Pande, P. Mohapatra and J.J. Han, Using deep learning for energy expenditure estimation with wearable sensors, in: 2015 17th International Conference on e-Health Networking, Application \& Services (HealthCom), 2015, pp. 501-506. doi:10.1109/HealthCom.2015.7454554. 